\title{
Desenvolvimento e Autonomia: Vetores da Política Externa brasileira
}

Development and Autonomy: Vectors of Brazilian Foreign Policy

\section{Reinaldo Alencar Domingues ${ }^{1}$}

\begin{abstract}
RESUMO
O presente texto investiga a complementaridade das noções de autonomia e desenvolvimento no trabalho teórico de Tullo Vigevani e Gabriel Cepaluni. Em seguida, avalia como as duas ideias foram computadas na concepção de interesse nacional na política externa de FHC e de Lula.
\end{abstract}

Palavras-Chave: Desenvolvimento; Autonomia; Política Externa.

\begin{abstract}
This paper investigates the complementarity of the notions of autonomy and development in the theoretical work of Tullo Vigevani and Gabriel Cepaluni. It then assesses how the two ideas were assimilated in the conception of national interest in the foreign policies of FHC and Lula.
\end{abstract}

Keywords: Development; Autonomy; Foreign Policy.

\section{INTRODUÇÃo}

Apesar de recente, a contribuição de Tullo Vigevani e Gabriel Cepaluni sobre a busca por autonomia como traço fundamental da política externa brasileira ganhou grande visibilidade e aceitação, sendo citada por inúmeros artigos. Os conceitos de autonomia pela distância, autonomia pela participação e autonomia pela diversificação foram acoplados rapidamente ao vocábulo da literatura acadêmica.

Os autores afirmam não desejar construir uma teoria sobre autonomia, mas apenas uma "interpretação plausível do mundo" fundada na observação histórica (VIGEVANI; CEPALUNI, 2011, p.37). Entretanto, ao observar o desenvolvimento da argumentação, fica claro que não se trata apenas de criar etiquetas para classificar a política externa de governos diferentes. A argumentação certamente contém traços

\footnotetext{
${ }^{1}$ Mestre em Relações Internacionais pela Universidade de Brasília (UnB) - Brasília, Brasil. Conjuntura Global, Vol. 4, n. 2, maio/ago., 2015, p. 250-261.
} 
teóricos. Os próprios autores constatam que os conceitos desenvolvidos por eles são "ferramentas analíticas importantes, que servem para simplificar fenômenos sociais complexos" (VIGEVANI; CEPALUNI, 2011, p.38). Inclusive, incentivam os demais acadêmicos a valerem-se de seus conceitos para analisar outros casos. Portanto, ao ser um esforço de compreensão teórica - ainda que ciente de seus limites de alcance - deve lidar com clareza os pressupostos que o fundamentam.

O presente artigo argumenta que a busca por autonomia nas relações internacionais só pode ser compreendida quando associada à busca por desenvolvimento. Apesar de Vigevani e Cepaluni lidarem de forma tangencial com o tema ao longo de sua obra, o nexo entre as duas ideias não é explicitado. Evidenciar esse pressuposto do modelo permite observar com maior precisão as variações estratégicas da política externa brasileira.

O texto se divide em três partes. Na primeira, é apresentada e problematizada a noção de autonomia colocada pelos autores. Na segunda parte, é exposta a base teórica a ser utilizada ao longo do trabalho, enfatizando a importância das ideias sobre o desenvolvimento como aspecto central da formulação da política externa brasileira. Em seguida, essa relação é explorada em uma análise do modelo de desenvolvimento e da estratégia de política externa no Brasil em dois momentos, nos governos de Fernando Henrique Cardoso e Lula.

\title{
Autonomia e o interesse nacional
}

Segundo Vigevani e Cepaluni (2011, p.34), autonomia é

\begin{abstract}
A condição que permite que os Estados formulem e implementem sua política externa independentemente do constrangimento imposto por Estados mais poderosos. Esse termo se insere em um continuum com dois tipos polares ideais: dependência total (ou alinhamento) e completa autonomia. Obviamente, entre os dois conceitos extremos existe uma gradação de políticas externas que combinam autonomia com dependência, embora, no caso brasileiro, a vertente autonomista seja mais marcante.
\end{abstract}

Nesse sentido, a definição dos autores tem dois aspectos centrais: a autodeterminação e o não-impedimento. Ser autônomo é definir por si próprio os objetivos a serem alcançados e os caminhos a serem perseguidos para atingi-los. Assim, Conjuntura Global, Vol. 4, n. 2, maio/ago., 2015, p. 250-261. 
no primeiro momento, é a habilidade de definir o que se deseja. Em seguida, a capacidade de agir em direção as metas delineadas. Todavia, a definição só ganha seu caráter pleno quando contraposto ao seu negativo. Agir com autonomia é ser independente. É não estar subordinado aos desejos e interesses de outros. Remete à capacidade de desobedecer ou neutralizar as influências externas sobre seu comportamento. Como ressaltam os autores, autonomia e dependência são polos de um eixo. Entre as extremidades, há infinitas possibilidades intermediárias que mesclam graus de ambos.

Apesar de ser um valor, autonomia não é um fim em si mesmo. A noção de independência parece incompleta sem referência a algum tipo de propósito. Ser livre para agir sem ser impedido está relacionado à vontade de conseguir o que se deseja. A subserviência é a frustração da vontade e da ação livres. Portanto, a autonomia não é um fim. É uma condição necessária para se alcançar algum objetivo. Nas relações internacionais, o mesmo raciocínio se reproduz. Vigevani e Cepaluni (2011) compartilham dessa visão, afirmando que a autonomia serve para ampliar o espaço de manobra para que o país busque seus interesses nacionais. Dessa forma, a finalidade da política exterior de um país não é buscar a autonomia. É defender o interesse nacional. Este, por sinal, só é possível na presença daquele. Sem autonomia, não pode haver interesse nacional. Mas a distinção entre condição e fim deve ser ressaltada.

Ao final, no que consiste o interesse nacional? Sobre esta questão, Renato Janine Ribeiro (2008) discorre: seria o interesse nacional um conceito ou uma noção? Em suas palavras, "o que caracteriza o conceito é que ele é preciso e a noção, imprecisa. Noções são vagas, rudimentares, polissêmicas, ambíguas, induzem ao erro. Já o conceito é elaborado com rigor. Ele é produtivo". A ideia de interesse nacional é sempre apresentada de forma vaga e imprecisa. Diante de toda a diversidade de interesses presentes na sociedade, como delimitar quais refletem o que é o melhor para a nação? Isso sugere que talvez o interesse nacional se aproxime mais da noção do que do conceito. Entretanto, o autor sugere que deveríamos deixar que a ideia de interesse nacional agisse tanto como conceito quanto como noção. No primeiro caso, trata-se de definir um mínimo denominador comum que serviria como norteador para a ação. Entretanto, tais ideias comuns podem ser interpretadas e reinterpretadas de inúmeras maneiras. Portanto, ao serem imprecisas e debatíveis, passam a se comportar como Conjuntura Global, Vol. 4, n. 2, maio/ago., 2015, p. 250-261. 
noções. Como tal, recuperam o espaço das discordâncias. Em síntese, "o conceito é o núcleo duro, mas leve; noções são as divergências que o rodeiam" (RIBEIRO, 2008).

Essa interpretação oferece duas vantagens. Em primeiro lugar, entender o interesse nacional apenas como noção torna-o improdutivo. A determinação do mínimo denominador comum estabelece os termos do debate e facilita a compreensão dos pontos de discórdia das diferentes interpretações. Em segundo lugar, deixar que essas ideias ajam como noções permite que coexistam diferentes perspectivas sobre os mesmos fins, preservando o caráter político do debate.

No caso do Brasil, quais seriam os componentes fundamentais do interesse nacional? Como citado, Vigevani e Cepaluni sugerem que a busca pela autonomia tem sido um traço constante da política externa brasileira ao longo da história. Entretanto, se a autonomia não é um fim em si mesmo, deve ser um meio para algo. Argumenta-se aqui que a ideia central que norteia a percepção de interesse nacional na política exterior brasileira é a busca pelo desenvolvimento. Quando contrapostas, a busca pelo desenvolvimento (fim) tem primazia sobre a busca por autonomia (meio). Dessa forma, as estratégias indicadas pelos autores para se alcançar autonomia (distância, participação e diversificação) só podem ser compreendidas quando inseridas no contexto da busca pelo desenvolvimento.

É necessário fazer alguns esclarecimentos. Em primeiro lugar, não é intenção com isso afirmar que os autores ignoram a relação entre desenvolvimento e autonomia na política externa brasileira. 0 reconhecimento da interação das duas ideias é perceptível em diversos trechos de suas obras. Entretanto, ao não tornarem essa ligação explícita em sua formulação teórica, obscurecem aspectos fundamentais da política externa brasileira. Por exemplo, se a meta é aumentar o espaço de autonomia, por qual razão ou sob quais circunstâncias - um país estaria disposto a aceitar um maior grau de dependência?

Em segundo lugar, não se está questionando a utilidade da contribuição dos autores. Pelo contrário, o argumento aqui desenvolvido visa ampliá-la, tornando explícito um pressuposto oculto. Dessa maneira, ao expor o que estava implícito, buscase esclarecer alguns dos aspectos da teoria, permitindo dar maior inteligibilidade aos dilemas estratégicos enfrentados pelo Brasil. 
Por último, não se questiona a importância da autonomia como diretriz da política externa brasileira. Contudo, afirma-se que este é um aspecto secundário e subordinado à busca pelo desenvolvimento. Na formulação dos autores, as estratégias para se alcançar a autonomia (distância, participação e diversificação) seriam meios para um meio. Constata-se aqui que a autonomia só tem sentido como condição para o desenvolvimento. Porém, como será argumentado em seguida, dependendo da noção de desenvolvimento adotada, a aceitação de certo grau de dependência também pode ser considerada condição para o desenvolvimento. Portanto, são as ideias sobre como buscar o desenvolvimento que determinam o equilíbrio entre autonomia e dependência. As ideias precedem a estratégia. São as ideias sobre meios e fins que dão sentido as noções de desenvolvimento e autonomia.

\section{Ideias e Política Externa Brasileira}

Segundo Keohane e Goldstein (1993, p.13), os interesses e as preferências dos Estados não são dados, mas adquiridos. As ideias cumprem a função de dar ordem ao mundo. Dão inteligibilidade a uma realidade complexa. A enorme quantidade de informações dificulta a compreensão da natureza e das relações sociais. As noções que desenvolvemos sobre como as coisas funcionam (causal beliefs), como deveriam funcionar (principled beliefs) e a natureza da realidade (worldview) simplificam a forma como interpretamos o universo, tornando-o cognoscível.

Isso se dá por dois processos. As ideias: i) limitam o universo de possibilidades; ii) permitem lidar com as incertezas. No primeiro caso, atuam definindo quais são as explicações e caminhos plausíveis. Consequentemente, também excluem logicamente todas as alternativas imprevistas. Limitam, portanto, a capacidade imaginativa dos atores. A interpretação que se faz do mundo fica sempre circunscrita ao campo reduzido do que é previsto pelas ideias como factível. 0 resto é obscurecido como impossibilidade ou equívoco. No segundo caso, as ideias tornam possível lidar com a incerteza. Em um contexto de informações incompletas sobre a realidade, as ideias ajudam a reduzir a incerteza ao estreitar o universo de possibilidades ou permitindo os atores a agir decisivamente respaldando-se em suas convicções morais (KEOHANE; GOLDSTEIN, 1993, p.16).

Conjuntura Global, Vol. 4, n. 2, maio/ago., 2015, p. 250-261. 
Nos dois casos, as ideias ajudam a dar sentido e significado à complexidade. Consequentemente, permitem construir entendimentos sobre sua posição na sociedade (identidade), suas preferências (interesses) e noções sobre relações de meios e fins (estratégia). Esses são os três pilares da ação do Estado. Essas noções explicam as escolhas de determinados caminhos em detrimentos de outros. São elas que criam expectativas de resultados que motivam o agir. Sem elas, restaria apenas a incerteza paralisante ou um comportamento desordenado de tentativa e erro. São as ideias, portanto, que permitem - e dão conteúdo - a ação.

0 presente estudo interessa-se particularmente pela relação entre as diferentes ideias sobre desenvolvimento e as estratégias de política exterior do Brasil. Sustenta-se que essa última tem como objetivo central buscar melhores condições para o desenvolvimento nacional. Diferentes noções sobre quais os caminhos mais adequados para alcançá-las afetam a formulação da política exterior brasileira. Conforme Maria Regina Soares de Lima e Mônica Hirst (2009, p.46),

\begin{abstract}
Considerações econômicas, e não militares ou de segurança, configuram os principais riscos e ameaças externas percebidas pelas elites. As principais vulnerabilidades externas são econômicas, e a política externa sempre teve um forte componente desenvolvimentista. Como resultado, o núcleo da agenda da política externa brasileira sempre foi predominantemente condicionado pelo modelo econômico vigente, e a evolução da política externa foi vinculada às conjunturas críticas do desenvolvimento de tal modelo.
\end{abstract}

Dessa forma, há uma estreita relação entre o modelo econômico vigente e a estratégia de inserção internacional do Brasil. As crenças sobre quais são os problemas enfrentados pela economia nacional e as prescrições sobre o que é necessário para superá-los influenciam o comportamento externo do País. A fim de analisar essa relação, serão observados os roadmaps - isto é, mapas mentais que expressam noções de causalidade que guiam as atores e geram expectativas de resultados - mantidos pelo modelo econômico liberal do governo FHC e pelo modelo neodesenvolvimentista do governo Lula. A partir disso, será possível verificar com maior clareza a relação entre tais modelos econômicos e as estratégias de busca de autonomia indicadas por Vigevani e Cepaluni, demonstrando que os primeiros têm primazia sobre os segundos. 


\section{Modelo Liberal e Autonomia pela Participação sob FHC}

O modelo econômico vigente no governo FHC é considerado liberal, ainda que de forma imperfeita. Pinheiro e Giambiagi (2006) afirmam que a economia brasileira durante o governo FHC passou por uma liberalização incompleta. Apesar de enfatizarem algumas reformas importantes em direção ao programa liberal, ressaltam que, enquanto alguns setores sofreram com uma abertura insuficiente, outros sofreram com o excesso. De outro lado, Cervo (2009) também indica a falta de "pureza" do liberalismo de FHC ao afirmar que seu governo foi marcado por uma "dança dos paradigmas". De qualquer modo, a inspiração é claramente liberal. Manteve uma política macroeconômica conservadora, definindo metas de inflação, mantendo o câmbio flutuante e estabelecendo o superávit primário. Simultaneamente, implantou políticas de liberalização comercial, desregulamentação financeira e reformas microeconômicas.

Segundo Pinheiro e Giambiagi (2006, p.8), esse modelo sustenta três premissas fundamentais: i) 0 setor privado é mais eficiente que o Estado; ii) $\mathrm{Na}$ impossibilidade do Estado fazer os investimentos necessários para sustentar o desenvolvimento, a iniciativa privada deveria assumir essa responsabilidade; iii) Dada a dificuldade do empresariado se financiar pelo mercado doméstico, o mercado internacional deveria ser explorado com esse fim, inclusive com maior abertura à participação direta do investimento estrangeiro.

Os autores deixam explícitas as noções de causalidade que sustentam o projeto liberal. De um lado, definem o que constitui um círculo vicioso de funcionamento da economia. Este se manifesta da seguinte maneira: Aumento do gasto público $\rightarrow$ Aumento de impostos $\rightarrow$ Baixo crescimento econômico $\rightarrow$ Aumento relação gasto/PIB $\rightarrow$ Pressão altista da carga tributárias (Retornando ao aumento de impostos). Do outro lado, o círculo virtuoso (liberal) segue a seguinte lógica: Controle do gasto público $\rightarrow$ Redução de Impostos $\rightarrow$ Estímulo à economia $\rightarrow$ Redução gasto/PIB $\rightarrow$ Possibilidade redução carga tributária (Retornando à redução de impostos). Dessa forma, a expansão de gastos considerados desnecessários tende a guiar o país para um crescimento lento e travado. Portanto, o Estado deve ter uma atuação seletiva na economia, agindo apenas nos espaços em que a ação do setor privado mostrar-se ineficaz ou inadequada. Em oposição, a diminuição dos impostos é compreendida como um poderoso estímulo Conjuntura Global, Vol. 4, n. 2, maio/ago., 2015, p. 250-261. 
econômico ao liberar recursos para que o setor privado aumente seus investimentos e aqueça a atividade econômica (PINHEIRO; GIAMBIAGI, 2006, p. 67). A partir de tais premissas, são estabelecidas três orientações econômicas gerais:

a) Criar condições para o desenvolvimento dos negócios, mediante a 'oferta' de estabilidade macroeconômica e de marco regulatório e legal adequado para os investimentos e as atividades do setor privado; b) Aproximar as condições para o desenvolvimento individual dos diversos membros da sociedade, no sentido de tornar menos desiguais as oportunidades de sucesso pessoal e profissional (...) c) Realizar investimentos e atividades econômicas necessárias para reduzir os gargalos que impedem o bom funcionamento da economia, enquanto e onde o Estado não for capaz de criar condições ao desenvolvimento desses negócios pelo setor privado. (PINHEIRO; GIAMBIAGI, 2006, p. 41).

Em outras palavras, podem-se elencar três objetivos fundamentais do modelo econômico liberal. Em primeiro lugar, melhorar o ambiente para os negócios. Isso implica em eliminar os obstáculos burocráticos excessivos, diminuir os custos de produção e erigir instituições estáveis. Em segundo lugar, incentivar o aumento da produtividade e oportunidades de inclusão social. Esse objetivo está relacionado a um conjunto de incentivos de ordem microeconômica - como melhoria das técnicas de gerenciamento, organização empresarial e difusão tecnológica - e ao fornecimento de serviços básicos que permitam o desenvolvimento das capacidades individuais e ofereça oportunidades. Por fim, construir credibilidade internacional. Na carência de poupança interna suficiente para manter o crescimento econômico, busca-se atrair o crédito e o investimento externo.

Esse modelo econômico está intimamente relacionado à estratégia de autonomia pela participação. Segundo Vigevani e Cepaluni (2011, p.93), a administração de FHC "visou internalizar, absorver e consolidar as mudanças liberalizantes que a globalização trouxe para a sociedade internacional durante os anos 1990". A política externa brasileira tinha como propósito criar condições favoráveis para facilitar e respaldar essa transição. Um ponto central do processo de abertura e liberalização econômica era o acesso ao crédito e investimentos externos. Para tanto, era necessário reconstruir a imagem do país no mundo. Nas palavras dos autores, 
O governo pretendia eliminar a percepção negativa do Brasil na comunidade internacional, especialmente no setor financeiro, e convencer seus parceiros de que o país estava preparado tanto para arcar com as obrigações da economia mundial quanto para tirar vantagens de seus benefícios. (VIGEVANI; CEPALUNI, 2011, p. 102).

Portanto, a reconstrução da imagem do país passava necessariamente pela adesão aos regimes internacionais. Na visão dos formuladores políticos, isso era facilitado pela recente convergência dos valores domésticos com os da sociedade internacional. 0 processo de democratização e a transição para uma economia de mercado permitiam uma aproximação relativa do país com os princípios sustentados pelas instituições internacionais do pós-Segunda Guerra Mundial. Entretanto, isso não significava a aceitação plena das regras. As discordâncias e protestos, porém, seriam lançados dentro das organizações - por um de seus membros. A ideia era tornar o Brasil um interlocutor legítimo nos quadros internacionais, valendo-se da Diplomacia e do Direito - em detrimento da lógica do poder - para resolver as controvérsias entre os

Estados e as distorções das regras das instituições. Essa perspectiva levava em consideração as limitações do poder brasileiro e o caráter benéfico das regras. Em outras palavras, a estratégia era ampliar o alcance e influenciar o caráter das regras a fim de diminuir as interações puramente de poder. Mesmo regras imperfeitas eram preferíveis à ausência de regras.

\section{Modelo Neodesenvolvimentista e a Autonomia pela Diversificação sob Lula}

O modelo econômico e a política externa do governo Lula podem ser compreendidos em duas fases, correspondentes ao primeiro e segundo mandatos do novo presidente. A primeira fase foi marcada pela continuidade das políticas econômicas do governo anterior e por novas ênfases na política externa. No primeiro caso, o receio quanto à ascensão de um governo de esquerda no Brasil intensificou as incertezas do mercado quanto ao País. O novo governo buscou, portanto, assegurar os credores e investidores estrangeiros, "repetindo fielmente as linhas básicas de política econômica do seu antecessor" (MAGALHÃES, 2010, p.21). Em relação à política externa, Lula deu continuidade e consolidou mudanças iniciadas no final do governo anterior - como a 
aproximação com os países emergentes e a mudança para um tom mais crítico da ordem internacional - adicionando novas ênfases: a necessidade de reforma da Carta da ONU, a expansão dos assentos permanentes do Conselho de Segurança e a democratização das instituições internacionais (VIGEVANI; CEPALUNI, 2011).

O segundo mandato de Lula foi marcado pela adoção do modelo econômico neodesenvolvimentista e pelo aprofundamento da estratégia de autonomia pela diversificação. No primeiro caso, o governo caminhou em direção ao "reconhecimento (...) de que (...) a simples ação das forças do mercado não é suficiente para promover o crescimento acelerado do PIB" (MAGALHÃES, 2010, p.22). O neodesenvolvimentismo pode ser sintetizado em quatro teses:

(1) não há mercado forte sem Estado forte; (2) não haverá crescimento sustentado [...] sem o fortalecimento ... do Estado e do mercado e sem implementação de políticas macroeconômicas adequadas; (3) mercado e Estados fortes somente serão construídos por um projeto nacional de desenvolvimento que compatibilize crescimento ... com equidade social; e (4) não é possível [reduzir] a desigualdade sem crescimento econômico a taxas elevadas e continuadas" (SICSÚ; PAULA; MICHEL, 2007, p. 509).

Em outras palavras, o modelo econômico do segundo mandato do governo Lula sustentava três ideias centrais (MORAIS; SAAD-FILHO, 2011). Em primeiro lugar, acredita-se na complementaridade entre Estado e mercado. Para que o mercado mantenha um funcionamento adequado e sustentável é necessário que haja um Estado forte o suficiente para garantir regulamentações que evite desequilíbrios. Opõe-se, assim, a visão liberal de que as interações livres do mercado tendem à estabilidade. Aqui, o papel do Estado é garantir as condições necessárias para o funcionamento dinâmico da economia. Em segundo lugar, crê-se que o desenvolvimento não ocorre automaticamente.

É necessário um projeto nacional de desenvolvimento para estimular os setores necessários para alcançar um crescimento econômico inclusivo e que resulte em um maior nível de igualdade social. 0 mercado, sozinho, pode agravar a concentração de renda e não melhorar a condição geral da sociedade. Por fim, acredita-se que $o$ desenvolvimento deve vir de dentro. Isto é, para se alcançar um crescimento sustentável é necessário o estímulo às forças internas de produção e inovação. Deve-se promover a poupança e o investimento domésticos e diminuir a dependência externa. 
A implantação do neodesenvolvimentismo foi acompanhada pelo aprofundamento da estratégia de autonomia pela diversificação no segundo mandato de Lula. Na visão de Cervo (2009, p.85), o paradigma implantado pelo governo "recupera a autonomia decisória da política exterior sacrificada pelos normais e adentra pelo mundo da interdependência, implantando um modelo de inserção pós-desenvolvimentista". Dessa forma, a busca por novas parcerias no cenário internacional cumpria também a função de mitigar a dependência externa e fortalecer o Estado para garantir a autonomia necessária para implantar um projeto nacional de desenvolvimento. Ainda que a autonomia pela diversificação tenham diversas outras dimensões estratégicas, fica patente sua complementaridade com o modelo econômico assumido internamente.

\section{CONSIDERAÇÕES FINAIS}

O panorama teórico criado por Vigevani e Cepaluni apresenta-se incompleto sem referências à busca pelo desenvolvimento. Como demonstrado ao longo do artigo, a autonomia não é um fim em si mesmo, mas uma condição para se alcançar o interesse nacional. Em termos da política externa, o desenvolvimento e a autonomia podem ser listados como componentes centrais do conceito de interesse nacional. Entretanto, as duas ideias se mantêm como noções dos quadros conceituais da diplomacia brasileira, permitindo múltiplas interpretações sobre seus significados e os caminhos (roadmaps) a serem percorridos para atingi-los. Nesse sentido, o ponto de equilíbrio entre os extremos de autonomia completa e dependência total é permeado pela noção de desenvolvimento.

Em síntese, o modelo criado pelos autores sobre a busca por autonomia se beneficia amplamente da noção de busca por desenvolvimento, permitindo dar maior inteligibilidade às variações estratégicas da política externa brasileira. Apesar de haver uma forte correlação entre o modelo de desenvolvimento e a política externa brasileira, esta não é uma interação determinista. De um lado, nota-se a relação de complementariedade da estratégia de autonomia pela participação e o modelo de desenvolvimento liberal na maior parte do governo FHC. De forma semelhante, é 
perceptível a simbiose da estratégia de autonomia pela diversificação e o neodesenvolvimentismo no segundo mandato do governo Lula.

Porém, fica patente também que o escopo das ações externas do País transcende o aspecto puramente instrumental de auxiliar na busca pelo desenvolvimento econômico. Isso é observável na mudança da política externa de FHC ao final de seu mandato sem grandes inflexões no modelo de desenvolvimento vigente. 0 mesmo se consta no primeiro mandato do governo Lula. A política externa é, portanto, também susceptível a mudanças na conjuntura internacional ou a alternâncias de governo.

\section{REFERÊNCIAS}

CERVO, Amado Luiz. Inserção Internacional: formação dos conceitos brasileiros. São Paulo: Ed. Saraiva, 2009.

GOLDSTEIN, Judith; KEOHANE, Robert. Ideas and Foreign Policy: Beliefs, Institutions and Political Change. Cornell University, 1993.

LIMA, Maria Regina Soares. HIRST, Mônica. Brasil como país intermediário e poder regional. In: HURRELL, Andrew et al. Os Brics e a ordem global. Rio de Janeiro: Editora FGV, 2009.

MAGALHÃES, João Paulo de Almeida. Estratégias e Modelos de Desenvolvimento. In: Os Anos Lula: contribuições para um balanço crítica 2003-2010. Rio de Janeiro: Garamond, 2010.

MORAIS, Lecio; SAAD-FILHO, Alfredo. Da economia política à política econômica:

o novo-desenvolvimentismo e o governo Lula. Revista de Economia Política, vol. 31, no 4 (124), pp. 507-527, outubro-dezembro, 2011

PINHEIRO, Armando Castelar; GIAMBIAGI, Fabio. Rompendo o marasmo: a retomada do desenvolvimento no Brasil. Rio de Janeiro: Elsevier, 2006.

RIBEIRO, Renato Janine. Sobre o conceito de interesse nacional. Interesse nacional, ano I, n. 2, p. 76-85, julho/setembro 2008.

SICSÚ, João; PAULA, Luiz Fernando de; MICHEL, Renaut. Por que novodesenvolvimentismo? Revista de Economia Política, Vol. 27, no 4, (108), pp.507-524 outubro-dezembro, 2007.

VIGEVANI, Tullo; CEPALUNI, Gabriel. Política Externa Brasileira: a busca da autonomia, de Sarney a Lula. São Paulo: UNESP 1º Ed. São Paulo, Editora Unesp, 2011 Conjuntura Global, Vol. 4, n. 2, maio/ago., 2015, p. 250-261. 